\title{
Effect of the Quenching Temperature on the Mechanical Behavior of P/M Hot Work Tool Steels
}

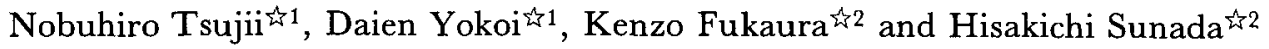 \\ 51 Technological Research Laboratory, Sanyo Special Steel Co., Ltd., 3007 Nakashima Shikama-ku, Himeji 672. \\ \&2 Faculty of Engineering, Himeji Institute of Technology, 2167 Shosha, Himeji 671-22. \\ Received July 18, 1995
}

\section{SYNOPSIS}

Effects of the quenching temperature on the mechanical properties at room temperature of two kinds of P/M hot work tool steels, AISI H11 standard grade and a newly developed grade, were investigated in comparison with conventional materials produced by ingot metallurgy. The tensile strength increased and the impact energy decreased with increasing the quenching temperature. However, the impact energy of $\mathrm{P} / \mathrm{M}$ materials quenched from $1403 \mathrm{~K}$ were much higher than that of $\mathrm{I} / \mathrm{M}$ materials. It was found from the results of instrumented Charpy impact tests that the approximately $80 \%$ of impact energy was exhausted for crack initiation. The impact fracture modes at the root of the notch were divided into three groups as follows: 1) ductile fracture paralleled to the direction of maximum shear stress, 2) ductile fracture with stretched zone and 3) brittle intergranular fracture. It was also found that the anisotropy impact energy in $\mathrm{P} / \mathrm{M}$ materials quenched from $1303 \mathrm{~K}$ resulted from broken stringer inclusions of $\mathrm{SiO}_{2}$.

KEY WORDS

P/M hot work tool steel, strength, toughness, instrumented Charpy impact test.

\section{Introduction}

Hot work tool steels produced by the conventional ingot metallurgy ( $/ \mathrm{M})$ show often anisotropy mechanical properties resulting from freezing segregation. In order to improve the properties of hot work tool steels, application of special melting process such as electroslag remelting process (ESR), and reduction of sulphur and phosphorus promoting microsegregation have been performed1). On the other hand, it is well known that the materials produced by the powder metallurgy (P/M) exhibit homogeneous and fine structures. $\mathrm{P} / \mathrm{M}$ process have been applied primarily for the production of advanced high-speed tool steels in the field of tool materials2).

In the previous study3), we reported that the austenite grain growth of AISI H11 hot work tool steel produced by $\mathrm{P} / \mathrm{M}$ process was suppressed even in the case of quenching from higher temperature, 1403K. Accordingly, we can expect that mechanical properties will be improved by the quenching from higher temperature than the standard temperature. In the present study, the tensile tests and the Charpy impact tests for both AISI H11 standard hot work tool steel and a newly developed grade $\mathrm{H} 11 \mathrm{M}$ designated in this paper which has a good temper resistance compared with H11 standard grade4) were carried out. Effects of the quenching temperature on these mechanical properties of the $P / M$ and $I / M$ steels were investigated.

\section{Experimental Procedures}

Table 1 gives the chemical compositions of steels used in this experiment. H11 steel is a standard hot work tool steel which is widely used for hot forging dies. H11M is a newly developed hot work tool steel which contains 
$\mathrm{Nb}$ and lower $\mathrm{Cr}$, higher $\mathrm{C}$ and higher Mo than H11 steel. As listed in Table 1, chemical compositions of materials used are the same except that each $\mathrm{P} / \mathrm{M}$ material have much higher oxygen and nitrogen contents than $\mathrm{I} / \mathrm{M}$ materials. $\mathrm{P} / \mathrm{M}$ materials with powder atomized by nitrogen gas were produced by hot extrusion. I/M materials were prepared by hot rolling from the conventionally produced ingot. The specimens were cut from bars with a diameter of $60 \mathrm{~mm}$ using a wire electric discharge machine after quenching and tempering. The quenching was carried out from two levels of temperatures, i.e. 1303 and $1403 \mathrm{~K}$ and double tempering was performed at $873 \mathrm{~K}$. Tensile tests with the plate specimen having dimensions $1.5 \times 2.0 \mathrm{~mm}$ in the gauge section were done at room temperature and the strain rate of $5.2 \times 10^{-4} \mathrm{sec}^{-1}$. Instrumented Charpy impact tests at room temperature were performed with the U-type notched impact specimen (notch radius, $\mathrm{R}=1 \mathrm{~mm}$ ). The fracture surfaces were studied using scanning electron microscope (SEM) and electron probe $\mathrm{X}$-ray microanalyser (EPMA).

Table 1 Chemical compositions.

(mass\%, O,N:ppm)

\begin{tabular}{|c|c|c|c|c|c|c|c|c|c|c|}
\hline \multicolumn{2}{|c|}{} & C & S i & Mn & C I & Mo & V & N b & O & N \\
\hline \multirow{3}{*}{ H 1 1 } & I /M & 0.35 & 1.02 & 0.41 & 4.99 & 1.21 & 0.49 & - & 12 & 165 \\
\cline { 2 - 11 } & P /M & 0.37 & 0.97 & 0.42 & 4.95 & 1.16 & 0.49 & - & 185 & 332 \\
\hline \multirow{2}{*}{ H 1 1 M } & I /M & 0.42 & 0.38 & 0.38 & 4.14 & 2.45 & 0.49 & 0.07 & 13 & 158 \\
\cline { 2 - 11 } & P /M & 0.41 & 0.41 & 0.40 & 4.19 & 2.53 & 0.50 & 0.07 & 80 & 349 \\
\hline
\end{tabular}

\section{Results and discussion}

\subsection{Tensile properties}

Figure 1 shows the relationship between the tensile properties at room temperature and the tempering hardness for each $\mathrm{P} / \mathrm{M}$ and $\mathrm{I} / \mathrm{M}$ material of both $\mathrm{H} 11$ and H11M steels. The test specimens were taken in the longitudinal direction from a center part of bars. As tempering hardness in all specimens increased with an increase of quenching temperature, the points of left and right side in Fig.1 represent the data of specimens quenched from $1303 \mathrm{~K}$ and $1403 \mathrm{~K}$, respectively. The $0.2 \%$ proof stress and tensile strength of each material increase with an increase of hardness. However, the strength of I/M materials of both steels quenched from $1403 \mathrm{~K}$ are a little lower than that of $\mathbf{P} / \mathbf{M}$ materials. The fracture surfaces of specimens quenched from $1303 \mathrm{~K}$ showed a shear lip and a transgranular ductile fracture with dimples irrespective of steel grade and production process. Figure 2 shows SEM micrographs of tensile fracture surfaces $(a, b)$ and optical micrographs of as-quenched microstructures of $\mathrm{H} 11 \mathrm{M}$ quenched from 1403K (c, d). The fracture surfaces of the $\mathrm{I} / \mathrm{M}$ materials of both steels quenched from 1403K showed a completely intergranular fracture (a) In the case of $\mathrm{P} / \mathrm{M}$ materials quenched from $1403 \mathrm{~K}$, the fracture surfaces were composed of an intergranular and a transgranular dimple fractures (b). The facet size of $\mathrm{P} / \mathrm{M}$ material (b)

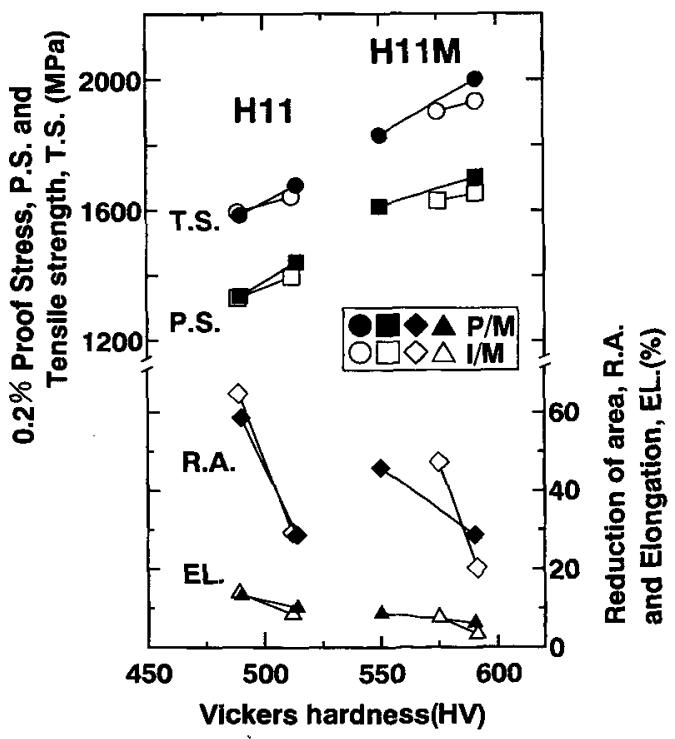

Fig.1 Relationship between tensile properties at room temperature and tempering hardness. 
is much smaller than that of $\mathrm{I} / \mathrm{M}$ material (a) as indicated in Fig.2. This behavior for fracture surfaces corresponds to the difference of parent austenite grain sizes of $\mathrm{I} / \mathrm{M}$ (c) and $\mathrm{P} / \mathrm{M}$ (d). In general, the yield strength is related to the grain size. It can be concluded that, as indicated in Fig.1, higher strength of $\mathrm{P} / \mathrm{M}$ materials than that of $\mathrm{I} / \mathrm{M}$ materials by quenching from high temperature results from finer grain as shown in Fig.2 (d).

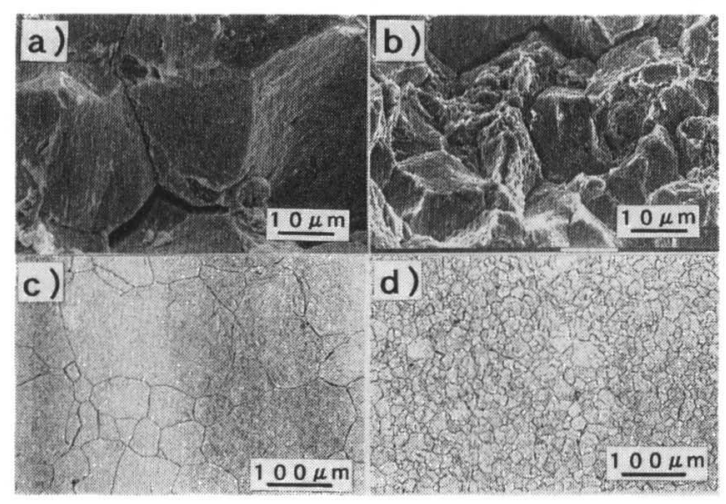

Fig.2 SEM of fracture surfaces of tensile specimens (a, b) and optical micrographs of as quenched microstructures of $\mathrm{H} 11 \mathrm{M}$ quenched from 1403K(c, d). (a, c): I/M, (b, d): P/M.

\subsection{Impact toughness}

\subsubsection{Absorbed energy}

Figure 3 shows an example of loaddeflection diagram obtained from an instrumented Charpy impact test. As indicated in Fig.3, the crack initiation energy: $E_{i}$ and crack propagation energy: $E_{p}$ were defined as the energy until the maximum load and the following energy, respectively. Figure 4 shows the relationship between crack initiation energy and total absorbed energy for all data in this study. As indicated in Fig.4, it is found that approximately $80 \%$ of the total absorbed energy is the crack initiation energy.

Figure 5 shows the relationship between Charpy impact energy, i.e., total absorbed energy, and tempering hardness. The test specimens were cut out in the longitudinal and transverse direction from a center part of bars. As explained in Fig.1, the points of right side of each material in Fig. 5 represent the data of specimens quenched from higher temperature, 1403K. From the results in Fig.5, we can find the following behavior irrespective of steel grade.

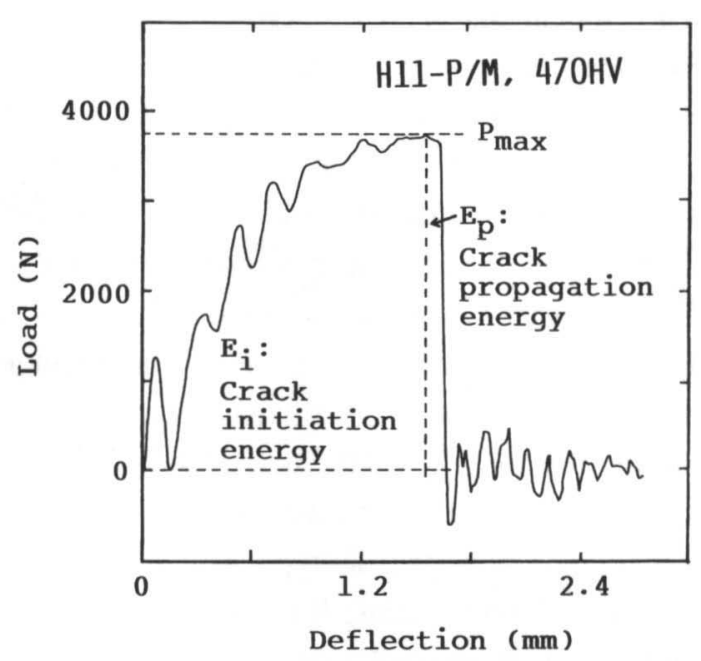

Fig.3 Example of load-deflection diagram obtained by instrumented Charpy impact test.

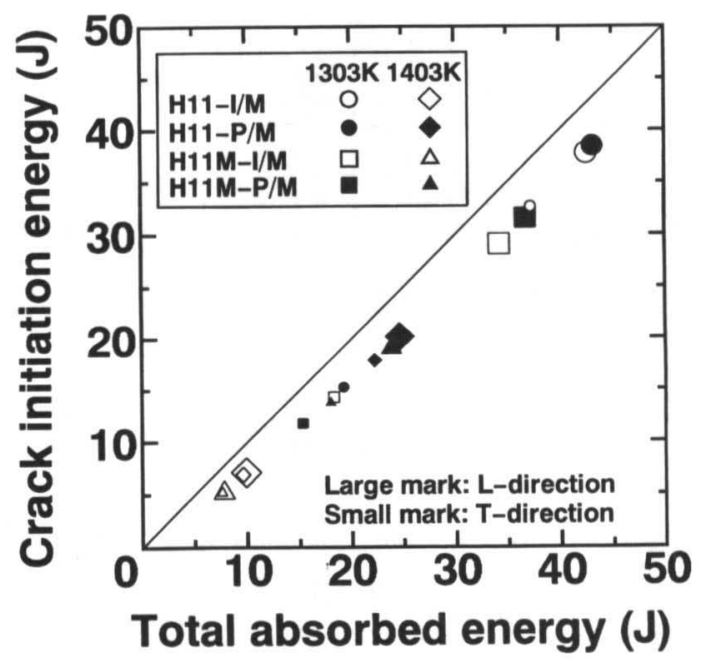

Fig.4 Relationship between crack initiation energy and total absorbed energy. 
(1) In the case of quenching from $1303 \mathrm{~K}$, the impact energy of transverse $\mathrm{P} / \mathrm{M}$ materials is lower than that of longitudinal P/M materials.

(2) Although the impact energy decreases with increasing hardness except for transverse $\mathrm{P} / \mathrm{M}$

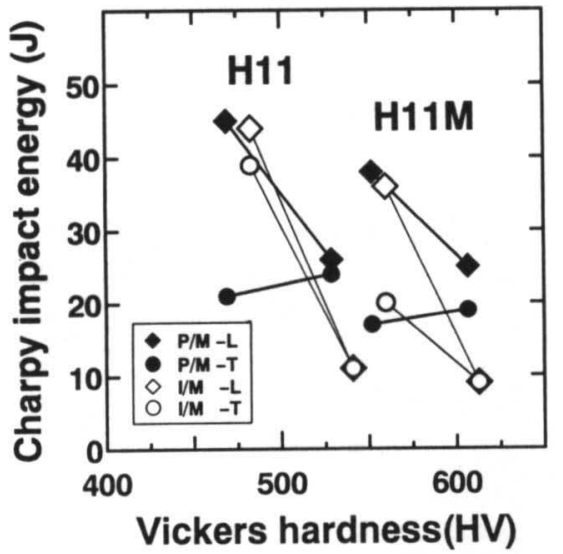

Fig.5 Relationship between Charpy impact energy at room temperature and tempering hardness. materials, the reduction in the energy for the $\mathrm{P} / \mathrm{M}$ materials is much smaller than that for the I/M materials.

(3) Impact energy of transverse $\mathrm{P} / \mathrm{M}$ materials quenched from $1303 \mathrm{~K}$ were much lower than that of $\mathrm{I} / \mathrm{M}$ materials.

Such behavior will be discussed later in detail in connection with the mode of fracture surface.

\subsubsection{Mode of fracture surface}

We described in Fig.4 that most of the absorbed energy was exhausted for the initiation of cracks. From the results of instrumented Charpy impact tests, we could also find that the fracture mode of crack initiation at the root of the notch were divided into three groups, type $\mathrm{A}, \mathrm{B}$ and $\mathrm{C}$ as shown in Fig.6. Table 2 summarized the classification of



Fig.6 Classification of impact fracture modes. 
Table 2 Classification of specimens based on impact fracture mode in Fig.6.

\begin{tabular}{|l|l|c|c|}
\hline Class & Specimens & $\begin{array}{l}\text { Quenching } \\
\text { temp. (K) }\end{array}$ & $\begin{array}{l}\text { Sampling } \\
\text { direction }\end{array}$ \\
\hline Type A & I/M, P/M & 1303 & L \\
\hline Type B & I/M, P/M & 1303 & T \\
& P/M & 1403 & L, T \\
\hline Type C & I/M & 1403 & L, T \\
\hline
\end{tabular}

L: Longitudinal, T: Transverse

specimen conditions, i.e., production process, quenching temperature and working direction, based on impact fracture mode in Fig.6. This classification can be applied to both $\mathrm{H} 11$ and H11M steels. The failure $c_{2}$ dssified as type A occurs after the satisfactory proceeding of the ductile fracture paralleled to the direction of maximum shear stress. As listed in Table 2 the longitudinal specimens quenched from $1303 \mathrm{~K}$ are classified as this type of fracture irrespective of production process. The characteristic of type B is that the failure occurs as soon as the applied load reaches the yield strength of materials. The fracture surface in the vicinity of notch shows so-called stretched zones) with tearing dimples. Figure 7 shows matching fractographs of the tearing dimples. In the case of type $\mathrm{C}$, fracture occurs suddenly before the yielding as shown in the load-deflection diagram of Fig.6. The fracture surface of type C shows intergranular fracture. The impact energy increases in the following order, type $C$, $\mathrm{B}$ and $\mathrm{A}$. This order is determined by the quantity of deflection to the initiation of crack.

\subsection{Toughness of $\mathbf{P} / \mathbf{M}$ materials}

Impact energy of transverse $\mathrm{P} / \mathrm{M}$ materials quenched from $1303 \mathrm{~K}$ was lower than that of $\mathrm{I} / \mathrm{M}$ materials as indicated in Fig.5. Both fracture mode were classified as type B as shown in Table 2. However, as indicated in Fig.8, large dimples placing in a row along the direction of crack propagation were observed only on the fracture surface of $\mathrm{P} / \mathrm{M}$ materials. It was found by EPMA analysis as indicated in Fig. 9 that such dimples result from nonmetallic inclusions of $\mathrm{SiO}_{2}$. It may be considered that such broken stringer inclusions of $\mathrm{SiO}_{2}$ were originally formed on the powder surface and were fragmented during hot extrusion. It is concluded that the low impact energy of

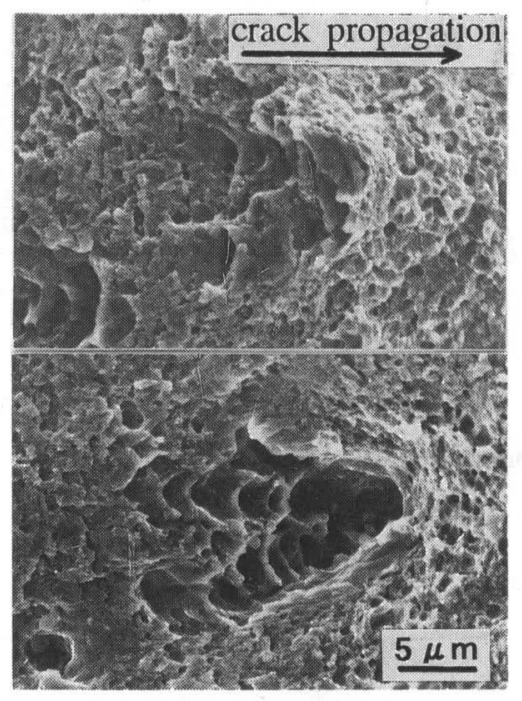

Fig.7 Matching fractograpghs showing the tearing dimples on the fracture surface of the specimen classified into type B. (P/M H11, 1303K, Tdirection.)

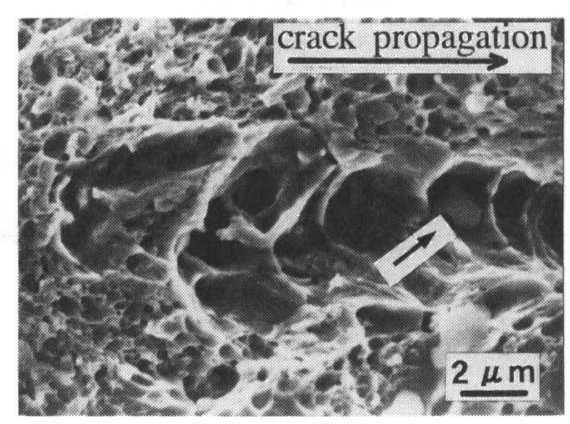

Fig.8 Continuously distributed dimples observed on the impact fracture surface of the transverse specimen of P/M H11 steel quenched from 1030K. The nonmetallic inclusions is indicated by the arrow. 
transverse $\mathrm{P} / \mathrm{M}$ materials quenched from $1303 \mathrm{~K}$ is attributed to the existence of such type of $\mathrm{SiO}_{2}$.

As indicated in Fig.5, the impact energy decreases with increasing hardness, i.e., increasing the quenching temperature. However, when quenching temperature is high, the impact energy of $\mathrm{P} / \mathrm{M}$ materials is much larger than that of the I/M materials. In particular, the impact energy of transverse $P / M$ materials is improved with an increase of quenching temperature. As shown in Table 2 the fracture of the I/M materials quenched from $1403 \mathrm{~K}$ was classified as type $C$. On the contrary, the fracture of $\mathrm{P} / \mathrm{M}$ materials quenched from $1403 \mathrm{~K}$ was classified as type B which showed stretched zone. It is concluded that the higher toughness of $\mathrm{P} / \mathrm{M}$ materials quenched from $1403 \mathrm{~K}$ results from the finer grain and the higher yield strength of $\mathrm{P} / \mathrm{M}$ materials.



Fig.9 EPMA analysis of the nonmetallic inclusions in dimples as shown in Fig.8.

\section{Conclusions}

Effects of the quenching temperature on mechanical properties of two kinds of $\mathrm{P} / \mathrm{M}$ hot work tool steels, AISI H11 standard grade and a newly developed grade, were investigated at room temperature compared with conventionally produced materials. Conclusions are obtained as follows:

1)All the tensile strength increase with an increase of the quenching temperature. A little improvement of strength is obtained for $P / M$ materials.

2)The approximately $80 \%$ of impact energy is exhausted for crack initiation.

3)The impact fracture modes are divided into three groups and the absorbed energy increases with increasing the quantity of deflection to the initiation of crack.

4)The impact energy decreases with an increase of the quenching temperature except for transverse $\mathrm{P} / \mathrm{M}$ materials, however, the impact energy of $\mathrm{P} / \mathrm{M}$ materials quenched from $1403 \mathrm{~K}$ are much higher than that of $\mathrm{I} / \mathrm{M}$.

5)P/M materials quenched from $1303 \mathrm{~K}$ have anisotropy impact energy because of broken stringer inclusions of $\mathrm{SiO}_{2}$.

6)Effects of the tempering temperature on the mechanical properties of two kinds of steels are the same.

\section{References}

1)E.Haberling and K.Rasche: Thyssen Edelst. Techn. Ber. (1983) 61 .

2)Metals Handbook 10th edition, ASM Int. 1 (1990) 780.

3)D.Yokoi, N.Tsujii, G.Abe, K.Fukaura and H.Sunada: J.Jpn.Soc.Powder and Powder Metall., 42 (1995) 481.

4)N.Tsujii, D.Yokoi, K.Fukaura, H.Sunada: and G.Abe: J.Jpn.Soc.Powder and Powder Metall., 42 (1995) 485.

5)H. Kobayashi and H. Nakamura: "Fractography", Ed., by R.Koterazawa et.al., Elsevier Applied Science (1990) 141. 